\title{
Molecular diagnosis and phylogenetic analysis of human papillomavirus type-16 from suspected patients in Pakistan
}

\author{
Abdullah Abdullahn,2,9, Muhammad Qasim ${ }^{1,2,10}$, Muhammad Shafiq ${ }^{1}$, Muhammad ljaz ${ }^{3}$, Shamsa Parveen ${ }^{4}$, \\ Shahnaz Murtaza ${ }^{5}$, Qamar Javed ${ }^{2}$, Salman Akbar Malik², Shahida Husain Tarar ${ }^{6}$, Sajid Mehmood ${ }^{7}$, Abdul Sami ${ }^{8}$, \\ Syed Muhammad Saqlan Naqvi ${ }^{8}$ and Muhammad Zeeshan Hyder ${ }^{1 *}$
}

\begin{abstract}
Background: Human Papillomavirus (HPV) is well known pathogen that can cause benign and malignant tumors in humans, yet there is very little information regarding HPV types prevalent in Pakistan.

Methods: A total of 92 cervical secretions were collected from suspected married female patients and used for DNA isolation using a novel isolation method. The samples were tested through Polymerase Chain Reaction (PCR) using already reported primers MY09/MY11, GP5/GP6, GP5+/GP6+, CP65/CP70, CP66/CP69 and SPF1/SPF2 and with those developed in this study including HRT1 and HRT2 primer sets for typing HPV types and HACTB primer set for human beta actin gene as internal positive control. Sequencing and phylogenetic analyses were performed for two isolates to determine circulating HPV types.

Results: PCR with HRT1 and HRT2 indicated 2 (2.17 \%) patients were positive for HPV type- 16 while 1 (1.08 \%) with HPV type 18. Sequencing and phylogenetic analysis of isolates confirmed HPV type-16 in genus alpha 9 which have $99 \%$ homology with already reported HPV from Japan and Costa Rica.

Conclusion: This is the first report of HPV type-16 genus alpha 9 in Pakistan and the reported assay and sequence data will serve as valuable tools in further epidemiological studies for HPV surveillance to improve public health, especially of females in Pakistan.
\end{abstract}

Keywords: Cervical carcinoma, Sexually Transmitted Diseases, Papillomavirus, Phylogenetic, Molecular epidemiology

\section{Background}

Human papillomaviruses (HPVs) are diverse, nonenveloped, double stranded DNA viruses which are sexually transmitted and belong to family Papillomaviridae. The family Papillomaviridae is very large and contains 16 genera [1] with virus species which infects humans, non-human mammals and reptiles. More than 120 species of this family infect humans belonging to five genera including Alphapapillomavirus, Betapapillomavirus, Gammapapillomavirus, Mupapillomaviurs and Nupapillomavirus of which genus Alphapapillomavirus is the biggest. About fifteen HPV types including HPV-

\footnotetext{
* Correspondence: zeeshan_hyder@comsats.edu.pk

'Department of Biosciences, COMSATS Institute of Information Technology, 45550 Islamabad, Pakistan

Full list of author information is available at the end of the article
}

16, $-31,-33,-35,-52,-58$, (belonging to species Human papillomavirus 16), $-18,-39,-45,-59,-68$, (Human papillomavirus 18), $-51,-82$ (Human papillomavirus 26) -73 (Human papillomavirus 34) and -56 (Human papillomavirus 53) [1] are considered "high risk" due to their association with malignant transformation $[2,3]$. The HPV type-16, followed by HPV type-18 are reported to be associated with $70 \%$ of invasive cervical cancer worldwide [4].

Infection with human papillomaviruses is directly associated with ano-genital cancer in both males and females $[5,6]$. The cervical cancer associated with HPV infection is the second most common cancer in women worldwide, with $8.2 \%$ mortality rate [7], and is the major cancer of women in most of the developing countries [8] where majority of the cervical cancer cases 
occur [7] due to the lack of health facilities to diagnose and treat the disease. Pakistan is one of the developing countries where social and religious taboos, the stigma associated with sexually transmitted diseases (STDs), and economic barriers are major hurdles in the fight against STDs. Furthermore, the awareness of STIs among sex-workers especially, and among nursing staff and interns in tertiary-care hospitals, in general [9] is almost zilch. The social demographics warrant wide spread epidemic of STIs in general population of Pakistan $[10,11]$ as anticipated for Human immunodeficiency virus (HIV) $[12,13]$.

HPV infection has been implicated in carcinomas of cervix [14-16], oral cavity [17] and lungs [18] in Pakistan as well as its DNA has been detected in general population $[15,19]$. The studies aiming to investigate prevalence of HPV utilize general primers for detection of HPV DNA. Currently most commonly used universal primers for HPV types are MY09/MY11 [20], GP5/GP6 [21], GP5+/GP6+ [22], CP65/CP70, CP66/CP69 [23], and SPF1/SPF2 [24] designed during 1990s or earlier. These primers were designed when sequence data of many of the currently known HPV genomes were not available as well as computation algorithm and power to reveal genome wide conserved regions were also not sufficiently advanced. Therefore, need existed to develop primers based on more rigorous analyses with larger sequence dataset which can not only detect more HPV types as well as can amplify sufficient proportion of HPV genome suitable for sequencing and phylogenetic analysis for rigorous confirmation of infecting type. Here we describe the development of a cheap method for HPV DNA isolation from small quantities of cervical secretions and novel primers designed for quality amplification of high risk HPV types. We also reported the sequence and phylogenetic analysis of two HPV isolates from Pakistan, which provided baseline information of molecular epidemiology of HPV in Pakistan.

\section{Results}

The DNA isolation method developed in this study consistently isolated about 0.5 to $1.0 \mu \mathrm{g}$ of DNA from cervical secretions with values greater than 1.7 for absorbance ratio of 260/280 $\mathrm{nm}$. The PCR analyses indicated that of 92 suspected married female patients of diverse age group and ethnicity, only $2(2.17 \%)$ patients tested positive for HPV type-16, while 1 (1.08 \%) was tested positive with HPV Type 18. The PCR amplification with already reported primer sets MY09/MY11, GP5/GP6, GP5+/GP6+, CP65/CP70, CP66/CP69, and SPF1/SPF2 were performed but showed no positive result, although the human actin beta gene was positively amplified using HACTB primer set. When these samples were tested with HRT1 and HRT2 novel primer sets, 3 out of 92 samples were found positive for HPV, two with HRT1 while other from HRT2 primer sets. Two out of these three positive samples were from a subset of two patients that were later diagnosed with cervical carcinoma, indicating a positivity of $100 \%$ (2 out of 2) in patients with cervical carcinoma. The positive samples using HRT1 were further cloned and sequenced which is deposited in the GenBank through accession number JX073135 and KU212390 under the name of HPV Pak01 and HPV Pak02 isolates respectively, while sample positive using HRT2 was not sequenced due to paucity of the infected DNA.

The sequence analysis of $1461 \mathrm{bp}$ fragment amplified by HRT1 primer set, of both Pak01 and Pak02, indicates that both are more than $99 \%$ identical to each other with only one synonymous mutation at 426 nt from G in Pak01 to A in Pak02. The phylogenetic analysis with sequences of other HPV types, revealed that both the isolates clusters with $100 \%$ bootstrap support with HPV type 16 reference sequence [25], among HPV 16 species (Fig. 1a) in genus alpha 9 ( $\alpha 9)$ [26]. Their relationship with other HPV type 16 isolates were further determined by BLAST analysis [27]. All the sequences of HPV 16 with full sequence coverage in BLAST analysis were extracted from GenBank and used for phylogenetic analysis (Fig. 1b). The phylogenetic analysis HPV 16 isolates indicated that HPV Pak01 and Pak02 clustered with $85 \%$ bootstrap value and more than $99 \%$ homology with isolates JP0278 and Qv00512 originated reportedly form Japan [28] and Costa Rica [29] respectively.

\section{Discussion}

Pakistan with a population of more than 180 million according to Population Census Organization of Pakistan (http://www.pbs.gov.pk/content/population-census) is the sixth most populous country in the world. Breast cancer is one of the most common cancers in the country with $13.8 \%$ incidence and $10.2 \%$ mortality followed by cervical cancer with $8.4 \%$ incidence and $7.2 \%$ mortality [7]. In current study we detected HPV in $3.26 \%$ of cases with gynecological problems, later on two of these three positive patients were diagnosed cervical cancer. Previously, the HPV positivity of $2.8 \%$ in general population, $27.3 \%$ in patient with cervical abnormalities [15] and $18 \%[16]$ to $98.33 \%[14,30]$ in cervical carcinoma patient has been reported for Pakistani population. Only, the primers sets (HRT1 \& HTR2) developed in this study showed positive results as compared to previously reported universal primers designed during 1990s.

HPV infection has been implicated in breast $[1,31]$ and cervical cancers [32, 33]. The detection of HPV types in cancer is commonly done by different PCR assays which utilize various universal primers including MY09/MY11 [20], GP5/GP6 [21], GP5+/GP6+ [22], 

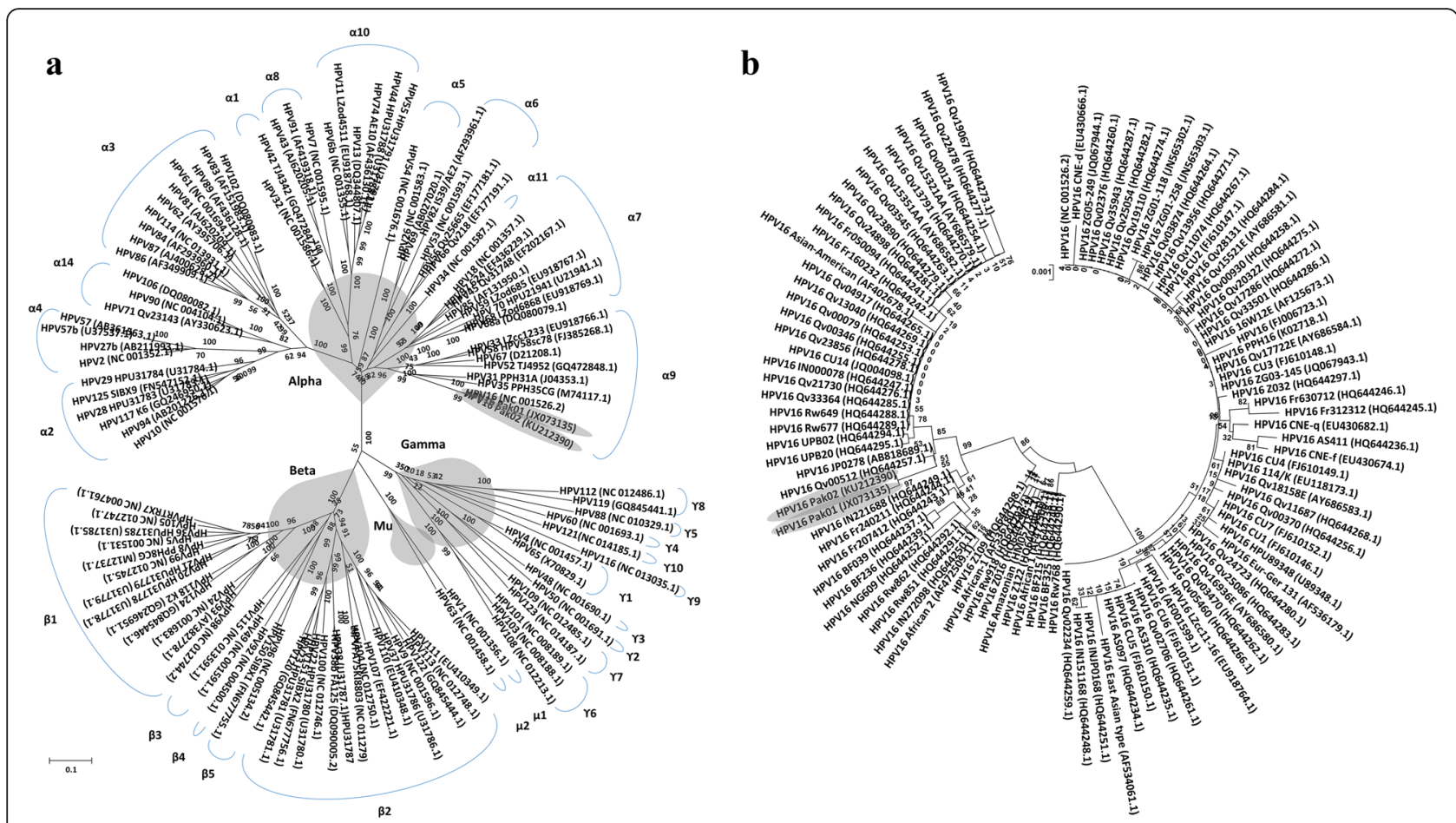

Fig. 1 Phylogenetic analyses of HPV isolate Pak01. a. The radiating NJ tree of HPV Pak01 and Pak02 with other HPV types having full-length genome sequences available from GenBank was constructed using MEGA version 5.05 [57]. The HPV Pak01 and Pak02 isolates (highlighted in gray) cluster with HPV type 16 reference sequence (accession no. NC_001526.2) with $100 \%$ bootstrap support, in HPV16 species which include HPV types 16, 31, 35, 33, 52,58 and 67 [1] and collectively belongs to a9 in genus alpha [26]. The annotation of species and genera in the tree follows Bernard and colleagues [26]. The bar indicates substitutions per site. $\mathbf{b}$. The circular NJ tree was generated by phylogenetic analysis of HPV Pak01 and Pak02 with HPV 16 isolates having full-length genome sequences available from GenBank. The HPV Pak01 and Pak02 isolate (highlighted in gray) clusters with HPV type 16 isolates JP02789 from Japan and Qv00512 from Costa Rica [29]. The bracket parenthesis indicates substitutions per site

CP65/CP70, CP66/CP69 [23], and SPF1/SPF2 [24] designed during 1990s or earlier. The specificities of these assays differ towards different types [34-36], which pose inconsistencies in detection and accurate determination of prevalence of various HPV types [34, 37, 38]. These inconsistencies might be one of the factors in the controversial reports of the presence of HPV in malignant tumors by some studies [5, 39-44] and absence by others'[45-48]. Therefore, development of primers capable of detecting more types is a crucial need. In addition, for epidemiological purposes it is of great importance to know the genetic sequence variability associated with virus population in that particular demographic and geographic region. These universal primers produce PCR products of less than $500 \mathrm{bp}$ which is not sufficient for phylogenetic based confirmation in particular for HPV which have low mutation [49] but significant recombination rates [50].

The HRT1 and HRT2 primer sets developed in this study are based on more rigorous analyses with larger sequence data set compared to already developed primers. An in-silico analysis using BLAST searches in non-redundant database indicated that both these primer set together can theoretically amplify about nine different HPV types belonging to high risk category, while the other primer sets are only capable of theoretically detecting seven (MY09/MY11) and four (GP5+/GP6+) high risk HPV types (Table 1). Interestingly, GP5 primer was not even been matched to any HPV sequence present in non-redundant database. These and other primers presented in Table 1 produce a PCR product of less than 500 bp except HRT1 and HRT2 primer sets which target a region of about $1460 \mathrm{bp}$ and about $1200 \mathrm{bp}$ respectively and provide sufficient sequence information to perform phylogenetic analysis for elucidation of HPV type reliably. Although thorough analysis with larger data set is required for an empirical comparison, nevertheless theoretical comparison using BLAST searchers and positive PCR amplification of two samples which were shown negative with previously reported primers, indicates the usefulness of these primer in HPV detection, specifically in those geographical regions where lack of information about genetic structure of circulating HPV types exists, such as Pakistan.

In population of Pakistan, although studies have been reported for the detection of HPV with in situ hybridization assay [51] and by PCR assay using universal primers [14-18, 30], sequence of any isolate and 
Table 1 In-silico analysis of primers sets using BLAST for detection of high risk human papillomavirus types

\begin{tabular}{|c|c|c|c|c|c|c|c|c|c|c|c|c|c|c|c|c|}
\hline \multirow[t]{2}{*}{ Primer sets } & \multirow[t]{2}{*}{ Sequence 5-'3' } & \multirow[t]{2}{*}{ Degenerate bases } & \multirow[t]{2}{*}{$\operatorname{Tm}\left({ }^{\circ} \mathrm{C}\right)$} & \multirow{2}{*}{$\begin{array}{l}\text { Product } \\
\text { size }(\mathrm{Kb})\end{array}$} & \multirow[t]{2}{*}{ Reference } & \multicolumn{11}{|c|}{ HPV Types } \\
\hline & & & & & & 16 & 18 & 31 & 33 & 35 & 39 & 45 & 52 & 56 & 58 & 59 \\
\hline HRT1 F & GACAGCGGRTATGGCAATWSTGAAG & 3 & 56 & $\simeq 1460$ & In this study & + & - & + & + & + & - & - & + & - & + & $\overline{-}$ \\
\hline HRT1 R & CCACGTCCTTGAGAAAAAGGATTTCC & 0 & & & & & & & & & & & & & & \\
\hline HRT2 F & GAGACACACCWGARTGGATACA & 2 & 56 & $\simeq 1200$ & In this study & - & + & - & - & - & - & + & - & + & - & - \\
\hline HRT1 R & CCATAGTTCCTCGCATGTRTCT & 1 & & & & & & & & & & & & & & \\
\hline MY09 & GCMCAGGGWCATAAYAATGG & 3 & 45 & $\simeq 450$ & {$[20]$} & + & + & + & + & - & + & - & - & - & + & + \\
\hline MY11 & CGTCCMARRGGAWACTGATC & 4 & & & & & & & & & & & & & & \\
\hline GP5 & TITGTTACTGGTAGATAC & 0 & 40 & $\simeq 140$ & {$[21]$} & - & - & - & - & - & - & - & - & - & - & - \\
\hline GP6 & GAAAAATAAACTGTAAATCA & 0 & & & & & & & & & & & & & & \\
\hline GP5+ & TITGTTACTGTGGTAGATACTAC & 0 & 40 & $\simeq 145$ & {$[22]$} & + & + & + & - & - & - & + & - & - & - & - \\
\hline GP6+ & GAAAAATAAACTGTAAATCATATTC & 0 & & & & & & & & & & & & & & \\
\hline CP65 & CARGGTCAYAAYAATGGYAT & 4 & 55 & $\simeq 465$ & {$[23]$} & $x$ & $x$ & $x$ & $x$ & $x$ & $x$ & $x$ & $x$ & $x$ & $x$ & $x$ \\
\hline CP70 & AAYTTTCGTCCYARAGRAWATTGRTC & 7 & & & & & & & & & & & & & & \\
\hline CP66 & AATCARMTGTTTRTTACWGT & 4 & 55 & $\simeq 385$ & {$[23]$} & $x$ & $x$ & $x$ & $x$ & $x$ & $x$ & $x$ & $x$ & $x$ & $x$ & $x$ \\
\hline CP69 & GWTAGATCWACATYCCARAA & 4 & & & & & & & & & & & & & & \\
\hline SPF1 & GCICARGGICAYAAYAATGG & 5 & 45 & $\simeq 65$ & {$[24]$} & $x$ & $x$ & $x$ & $x$ & $x$ & $x$ & $x$ & $x$ & $x$ & $x$ & $x$ \\
\hline SPF2 & GTIGTATCIACWACAGTAACAAA & 3 & & & & & & & & & & & & & & \\
\hline
\end{tabular}

The non-redundant/nucleotide collection (nr) database at National Center of Biotechnology Information (NCBI at http://www.ncbi.nlm.nih.gov/) was searched with the sequence of each primer by nucleotide Blast [27] using default values except maximum target sequences value was selected to 20,000. (+) means that both of the primers in a pair have secured blast hits for a particular HPV types mentioned above, while (-) means that one or both of the primers in a set have not been able to secure any blast hit for a particular HPV types. Due to the presence of many degenerate bases in the primer sequences, the Blast analysis was not been successful for primer sets CP65 \& CP70, CP66 \& CP69 and SPF1 \& SPF2 and is represented by (x). The GP6 primer showed no hit specific to HPV. The product sizes are not exact and may differ slightly depending on the HPV types. The results in the table are based on Blast analysis only and may differ considerably compared to published results or when used empirically, therefore, please refer to the given references for exact details of HPV types amplified by each primer set

confirmation of circulating HPV types by sequencing and phylogenetic analysis was never reported. The phylogenetic analysis of current study confirmed that isolate Pak01 from a female patient suffering from cervical cancer and Pak02 from a female in Gujrat, belong to HPV type-16, and falls under Human papillomavirus 16 species in genus alpha 9 of Papillomaviridae. The close phylogenetic relationship and $99 \%$ nucleotide identity of these isolates with isolates from Japan and Costa Rica [29] indicate the probable role of expatriates in the spread of HPV across the world. The role of expatriates in spreading STIs such as HIV has been already been reported $[52,53]$ which had lead HIV to a verge of big epidemic in Pakistan [12].

The majority of population in Pakistan is living in poor socio-economic demography with little accessibility to quality medical care. In addition, social and religious taboos and stigma associated with sexually transmitted diseases offer great hindrance in studying and managing STIs. The studies on STIs with tracing of infection origin through phylogenetic analysis can help in identify the active transmitting group as well as risk groups and may lead pinpoint interventions for early diagnosis and blocking of disease transmission to healthy population.

\section{Methods}

In this study 92 married female patients that were suspected for HPV of diverse age group and ethnicity, reporting various gynecological problems at three hospitals including Nuclear Medicine, Oncology and Radiotherapy Institute (NORI), Islamabad, Benazir Bhutto Shaheed (BBS) Hospital, Rawalpindi and Nawaz Sharif Medical College (NSMC), University of Gujrat, Gujrat, were included. The study was approved by the ethical committees at COMSATS Institute of Information Technology (CIIT), NORI, BBS and NSMC. Cervical secretion was collected after taking informed consents from the patients with the help of gynecologist using aseptic vaginal cotton swabs. DNA was extracted using a novel CTAB-Guanidine thiocyanate method. Briefly, $0.5-1.0 \mathrm{ml}$ of $2 \%$ CTAB buffer $(100 \mathrm{mM}$ Tris $-\mathrm{HCl}$ $\mathrm{pH}$ 8.0, $2 \%(\mathrm{w} / \mathrm{v})$ CTAB, $20 \mathrm{mM}$ EDTA, $1.4 \mathrm{M} \mathrm{NaCl}$, and $1 \%(\mathrm{v} / \mathrm{v}) \beta$-mercaptoethanol) was added in the swab container and homogenized using swab stick with cervical secretion for 2-3 min, for maximum sample recovery. About $0.5 \mathrm{ml}$ of the mixture was transferred into eppendorf tubes and was added with $0.5 \mathrm{ml}$ of $4 \mathrm{M}$ guanidine thiocyanate solution and $0.7 \mathrm{ml}$ of chloroform, mixed thoroughly and centrifuged at $16,000 \mathrm{~g}$ for $10 \mathrm{~min}$. 0.1 volume of $3 \mathrm{M}$ sodium acetate was added to 
the supernatant and mixed which then followed by the addition of isopropanol in equal quantity and centrifugation at $16,000 \mathrm{~g}$ for $5 \mathrm{~min}$. After discarding the supernatant, the DNA pellet was washed twice with $70 \%$ $(\mathrm{v} / \mathrm{v})$ ethanol and dissolved in 0.1× TAE Buffer containing RNase. The appropriateness of DNA isolation was confirmed by PCR amplification of a fragment of human actin beta gene from chromosome number 7 (accession number NG_007992.1) using primer set (HACTB F: 5' -CACAG TAGGTCTGAACAGACTC-3' (position 6742-6763) and HACTB R: 5'-AGTGATCTCCTTCTGCATCCTG-3' (position 7568-7547) as positive control. The samples were amplified with MY09/MY11 following procedure described by Manos and colleagues [20], with GP5/GP6 following Snijders and colleagues [21], with GP5+/GP6+ as described by de Roda Husman and colleagues [22], with CP65/CP70, and CP66/CP69 following Berkhout and colleagues [23], and with SPF1/SPF2 as reported by Kleter and colleagues [24].

Two novel primer sets HRT1 and HRT2 were developed by finding conserved regions in HPV genomes using about 90 full-length genomic sequences belonging to high risk HPV types $16,18,31,33,35,45,52,56,58$, 59, 68 and 69 downloaded from GenBank and then aligned using MAFFT version 6.864 [54] which utilizes progressive and iterative refinement heuristic methods for large genomic sequences. Depending upon the genomic variability two sets of primers were designed i.e. HRT1 \{HRT1 F: 5'-GACAGCGGRTATGGCAATWST GAAG-3' (position 1254-1278 of type 16 reference genome accession NC_001526.2) and HRT1 R: 5' -CCACGTC CTTGAGAAAAAGGATTTCC-3' (position 2714-2689 of type 16 reference genome accession NC_001526.2) which can detect types $16,31,33,35,52$ and 58 and HRT2 \{HRT2 F: 5'-GAGACACACCWGARTGGA TACA-3' (position 1935-1956 of type 18 reference genome accession NC_001357.1) and HRT2 R: 5'-CCA TAGTTCCTCGCATGTRTCT-3' (position 3134-3113 of type 18 reference genome accession NC_001357.1) which can detect types 18, 45, 56, 59, 68 and 69.

PCR reaction contained about 50 ng DNA template, Taq buffer $(10 \mathrm{mM}$ Tris- $\mathrm{HCl}, \mathrm{pH} 8.8,50 \mathrm{mM} \mathrm{KCl}$ and $0.08 \%$ (v/v) Nonidet P40) $1.5 \mathrm{mM} \mathrm{MgCl} 2,200 \mu \mathrm{M}$ of each dNTPs, 1.5 units Taq DNA Polymerase (recombinant) (Fermentas, UAB Lithuania), and $50 \mathrm{pM}$ of each primer. The thermal profile for all primer sets included pre-PCR denaturation at $96{ }^{\circ} \mathrm{C}$ for 3 min followed by 35 cycles of denaturing at $96{ }^{\circ} \mathrm{C}$ for $20 \mathrm{~s}$, annealing at $56{ }^{\circ} \mathrm{C}$ for $20 \mathrm{~s}$ and extension at $72{ }^{\circ} \mathrm{C}$ for $2.5 \mathrm{~min}$, and a final extension at $72{ }^{\circ} \mathrm{C}$ for $20 \mathrm{~min}$. The PCR products were analyzed using standard $1 \%$ agarose gel electrophoresis.

The PCR product of HPV 16 isolate was cloned into pTZ57R (InsTA Cloning Kit, Fermentas UAB Lithuania), according to the manufacturer's instructions, and transformed into Escherichia coli DH5 $\alpha$ cells by electroporation. The cells were selected on ampicillin containing Luria-Bertani (LB) agar plates and screened for $\beta$ glucoronidase expression. Plasmid DNA was extracted using a minipreparation protocol according to Sambrook and Russell [55], and confirmed by digestion with restriction endonucleases. The plasmid DNA containing cloned fragment from three different independent clones, was sequenced using commercial sequencing facility of Macrogen (Korea) using M13 universal primers and gene specific primers. The sequence data was compiled using DNA Dragon Sequence Assembler version 1.5.1 (Sequentix-Digital DNA Processing, Germany).

Phylogenetic analysis was performed on alignments produced through MAFFT version 6.864 [54] to obtain Neighbor-Joining (NJ) trees using Kimura's two-parameter model [56] implemented in in the Molecular Evolutionary Genetics Analysis Program (MEGA) version 5.05 [57]. Phylogeny reconstruction test was performed using 1000 bootstrap replicates.

\section{Conclusions}

In conclusion, the study suggests the presence of HPV in $3.26 \%$ of cervical sample secretions analyzed from Pakistani patients using two novel primer sets i.e. HRT1 and HRT2 developed by rigorous analysis of conserved regions in a large data set of HPV genomes. Isolates Pak01 and Pak02 originated from two female patients belonging to different geographical regions were sequenced for the first time using HRT1 primer set and their phylogenetic analysis suggests their belonging to genus alpha 9 of HPV type-16. The reported primers and sequence generated in this study will serve as foundation for further epidemiological studies for HPV surveillance in Pakistan.

\section{Competing interests \\ The authors declare that they have no competing interests.}

\section{Authors' contributions}

AA, MQ and MS: Data collection and molecular work. SP, SM and SHT: collecting samples and data analysis. QJ, SAM SM, AS and SMSN: Data analysis and manuscript preparation. MZH: Study design, data analysis, lab provision and manuscript preparation. All authors read and approved the final manuscript.

\section{Acknowledgements}

We are grateful for financial assistance to M. Zeeshan Hyder though NRPU grant number 1558 from Higher Education Commission, Pakistan.

\section{Author details}

${ }^{1}$ Department of Biosciences, COMSATS Institute of Information Technology, 45550 Islamabad, Pakistan. ${ }^{2}$ Department of Biochemistry, Quaid-i-Azam University Islamabad, Islamabad, Pakistan. ${ }^{3}$ Department of Clinical Medicine and Surgery, University of Veterinary and Animal Sciences-Lahore, Lahore, Pakistan. ${ }^{4}$ Department of Obstetrics and Gynecology, Benazir Bhutto Hospital Rawalpindi, Rawalpindi, Pakistan. ${ }^{5}$ Department of Clinical Diagnostics, Nuclear Oncology and Radiotherapy Institute, Islamabad, Pakistan. ${ }^{6}$ Department of Obstetrics and Gynecology, Nawaz Sharif Medical College, University of 
Gujrat, Gujrat, Pakistan. ${ }^{7}$ Department of Biochemistry and Molecular Biology, Nawaz Sharif Medical College, University of Gujrat, Gujrat, Pakistan. ${ }^{8}$ Department of Biochemistry, PMAS Arid Agriculture University Rawalpindi, Rawalpindi, Pakistan. ${ }^{9}$ Department of Integrative Engineering, Chung Ang University, Seoul, South Korea. ${ }^{10}$ Immune Network Pioneer Research Centre, School of Medicine, Ajou University, Suwon, South Korea.

Received: 12 September 2015 Accepted: 6 January 2016

Published online: 12 January 2016

\section{References}

1. de Villiers EM, Bernard HU, Broker T, Delius H, Zur HH. Papillomaviridae. In: Fauquet CM, Mayo MA, Maniloff J, Desselberger U, Ball LA, editors. In virus taxonomy: eighth report of the international committee on taxonomy of viruses. San Diego: Elsevier Academic Press; 2005. p. 343-52.

2. Munoz N, Bosch FX, de Sanjose S, Herrero R, Castellsague X, Shah KV, et al. Epidemiologic classification of human papillomavirus types associated with cervical cancer. N Engl J Med. 2003;348(6):518-27. doi:10.1056/NEJMoa021641.

3. Clifford GM, Smith JS, Plummer M, Munoz N, Franceschi S. Human papillomavirus types in invasive cervical cancer worldwide: a meta-analysis. Br J Cancer. 2003;88(1):63-73. doi:10.1038/sj.bjc.6600688.

4. de Sanjose S, Diaz M, Castellsague X, Clifford G, Bruni L, Munoz N, et al. Worldwide prevalence and genotype distribution of cervical human papillomavirus DNA in women with normal cytology: a meta-analysis. Lancet Infect Dis. 2007;7(7):453-9. doi:10.1016/S1473-3099(07)70158-5.

5. Walboomers JM, Jacobs MV, Manos MM, Bosch FX, Kummer JA, Shah KV, et al. Human papillomavirus is a necessary cause of invasive cervical cancer worldwide. J Pathol. 1999;189(1):12-9. doi:10.1002/(SICI)1096-9896(199909)189: 1<12:AID-PATH431>3.0.CO;2-F.

6. Stone KM, Karem KL, Sternberg MR, McQuillan GM, Poon AD, Unger ER, et al. Seroprevalence of human papillomavirus type 16 infection in the United States. J Infect Dis. 2002;186(10):1396-402. doi:10.1086/344354.

7. Ferlay J, Shin HR, Bray F, Forman D, Mathers C, Parkin DM. GLOBOCAN 2008 v2.0, Cancer Incidence and Mortality Worldwide: IARC CancerBase No. 10. [Internet]. Lyon, France: International Agency for Research on Cancer; 2010. http://globocan.iarc.fr. Accessed 10 Mar 2012.

8. Bray F, Ren J-S, Masuyer E, Ferlay J. Global estimates of cancer prevalence for 27 sites in the adult population in 2008. Int J Cancer. 2013;132(5):1133-45. doi:10.1002/ijc.27711.

9. Ali SF, Ayub S, Manzoor NF, Azim S, Afif M, Akhtar N, et al. Knowledge and awareness about cervical cancer and its prevention amongst interns and nursing staff in Tertiary Care Hospitals in Karachi, Pakistan. PLoS One. 2010; 5(6):e11059. doi:10.1371/journal.pone.0011059.

10. Maan MA, Hussain F, lqbal J, Akhtar SJ. Sexually transmitted infections in Pakistan. Ann Saudi Med. 2011;31(3):263-9.

11. Sheikh Zl, Mashood AA. Increaseing trends of sexually transmitted disease a reality. J Pak Assoc Dermatol. 2010;20:191-3.

12. Rai M, Warraich $\mathrm{H}$, Ali $\mathrm{S}$, Nerurkar V. HIV/AIDS in Pakistan: the battle begins. Retrovirology. 2007;4(1):1-3. doi:10.1186/1742-4690-4-22.

13. Khan OA, Hyder AA. Responses to an emerging threat: HIV/AIDS policy in Pakistan. Health Policy Plan. 2001;16(2):214-8. doi:10.1093/heapol/16.2.214.

14. Khan S, Jaffer NN, Khan MN, Rai MA, Shafig M, Ali A, et al. Human papillomavirus subtype 16 is common in Pakistani women with cervical carcinoma. Int J Infect Dis. 2007;11(4):313-7. doi:10.1016/j.jijd.2006.06.007.

15. Raza SA, Franceschi S, Pallardy S, Malik FR, Avan BI, Zafar A, et al. Human papillomavirus infection in women with and without cervical cancer in Karachi, Pakistan. Br J Cancer. 2010;102(11):1657-60. doi:10.1038/sj.bjc. 6605664.

16. Yousuf S, Syed S, Moazzam A, Lucky MH. Frequency of high risk human papillomavirus types in squamous cell carcinoma of cervix among women. JPMA. 2010;60(3):193-6.

17. Ali SMA. Human Papillomavirus (HPV) Association and P53 mutation in oral cavity (Squamous Cell Carcinoma) cancers of Pakistani patients: it's correlation with Histologic variables \& disease out come. Karachi, Pakistan: Baqai Medical University; 2008.

18. Aguayo F, Anwar M, Koriyama C, Castillo A, Sun Q, Morewaya J, et al. Human papillomavirus-16 presence and physical status in lung carcinomas from Asia. Infect Agents Cancer. 2010;5:20. doi:10.1186/1750-9378-5-20.

19. Gichki AS, Buajeeb W, Doungudomdacha S, Khovidhunkit SO. Detection of human papillomavirus in normal oral cavity in a group of Pakistani subjects using real-time PCR. Asian Pacific J Cancer Preve. 2012;13(5):2299-304.
20. Manos MM, Ting Y, Wright DK, Lewis AJ, Broker TR, Wolinsky SM. The use of polymerase chain reaction amplification for the detection of genital human papillomaviruses. Cancer Cells. 1989;7:209-14.

21. Snijders PJ, van den Brule AJ, Schrijnemakers HF, Snow G, Meijer CJ, Walboomers JM. The use of general primers in the polymerase chain reaction permits the detection of a broad spectrum of human papillomavirus genotypes. J Gen Virol. 1990;71(Pt 1):173-81.

22. de Roda Husman AM, Walboomers JM, van den Brule AJ, Meijer CJ, Snijders PJ. The use of general primers GP5 and GP6 elongated at their $3^{\prime}$ ends with adjacent highly conserved sequences improves human papillomavirus detection by PCR. J Gen Virol. 1995;76(Pt 4):1057-62.

23. Berkhout RJ, Tieben LM, Smits HL, Bavinck JN, Vermeer BJ, ter Schegget J. Nested PCR approach for detection and typing of epidermodysplasia verruciformis-associated human papillomavirus types in cutaneous cancers from renal transplant recipients. J Clin Microbiol. 1995;33(3):690-5.

24. Kleter B, van Doorn $L$, ter Schegget J, Schrauwen L, van Krimpen K, Burger $M$, et al. Novel short-fragment PCR assay for highly sensitive broadspectrum detection of anogenital human papillomaviruses. Am J Pathol. 1998;153(6):1731-9. doi:10.1016/S0002-9440(10)65688-X.

25. Seedorf K, Krammer G, Durst M, Suhai S, Rowekamp WG. Human papillomavirus type 16 DNA sequence. Virology. 1985;145(1):181-5.

26. Bernard HU, Burk RD, Chen Z, van Doorslaer K, Zur Hausen H, de Villiers EM. Classification of papillomaviruses (PVs) based on $189 \mathrm{PV}$ types and proposal of taxonomic amendments. Virology. 2010;401(1):70-9. doi:10.1016/j.virol. 2010.02.002.

27. Altschul SF, Madden TL, Schäffer AA, Zhang J, Zhang Z, Miller W, et al. Gapped BLAST and PSI-BLAST: a new generation of protein database search programs. Nucleic Acids Res. 1997;25(17):3389-402. doi:10.1093/nar/25.17.3389.

28. Kukimoto I, Maehama T, Sekizuka T, Ogasawara Y, Kondo K, KusumotoMatsuo R, et al. Genetic variation of human papillomavirus type 16 in individual clinical specimens revealed by deep sequencing. PLoS One. 2013; 8(11):e80583. doi:10.1371/journal.pone.0080583.

29. Schiffman M, Herrero R, Desalle R, Hildesheim A, Wacholder S, Rodriguez AC, et al. The carcinogenicity of human papillomavirus types reflects viral evolution. Virology. 2005;337(1):76-84. doi:10.1016/j.virol.2005.04.002.

30. Khan S. Molecular epidemiology of Human Immunodeficiency Virus (HIV) and Human Papillomavirus (HPV) in Pakistan. Karachi, Pakistan: University of Karachi; 2010.

31. Wang T, Chang P, Wang L, Yao Q, Guo W, Chen J, et al. The role of human papillomavirus infection in breast cancer. Med Oncol. 2012;29(1):48-55. doi:10.1007/s12032-010-9812-9.

32. zur Hausen H. Human papillomavirus \& cervical cancer. Indian J Med Res. 2009;130(3):209.

33. zur Hausen $\mathrm{H}$. Papillomaviruses and cancer: from basic studies to clinical application. Nat Rev Cancer. 2002;2(5):342-50. doi:10.1038/nrc798.

34. Harnish DG, Belland LM, Scheid EE, Rohan TE. Evaluation of human papillomavirus-consensus primers for HPV detection by the polymerase chain reaction. Mol Cell Probes. 1999;13(1):9-21. doi:10.1006/mcpr.1998.0203.

35. Karlsen F, Kalantari M, Jenkins A, Pettersen E, Kristensen G, Holm R, et al. Use of multiple PCR primer sets for optimal detection of human papillomavirus. J Clin Microbiol. 1996;34(9):2095-100.

36. Depuydt CE, Boulet GA, Horvath CA, Benoy IH, Vereecken AJ, Bogers JJ. Comparison of MY09/11 consensus PCR and type-specific PCRs in the detection of oncogenic HPV types. J Cell Mol Med. 2007;11(4):881-91. doi:10.1111/j.1582-4934.2007.00073.x.

37. Gravitt PE, Peyton CL, Alessi TQ, Wheeler CM, Coutlee F, Hildesheim A, et al. Improved amplification of genital human papillomaviruses. J Clin Microbiol. 2000;38(1):357-61.

38. Qu W, Jiang G, Cruz Y, Chang CJ, Ho GY, Klein RS, et al. PCR detection of human papillomavirus: comparison between MY09/MY11 and GP5+/GP6+ primer systems. J Clin Microbiol. 1997;35(6):1304-10.

39. Di Lonardo A, Venuti A, Marcante ML. Human papillomavirus in breast cancer. Breast Cancer Res Treat. 1992;21(2):95-100.

40. zur Hausen H. Papillomaviruses in human cancers. Proc Assoc Am Physicians. 1999;111(6):581-7.

41. Yu Y, Morimoto T, Sasa M, Okazaki K, Harada Y, Fujiwara T, et al. Human papillomavirus type 33 DNA in breast cancer in Chinese. Breast Cancer. 2000;7(1):33-6.

42. Liu Y, Klimberg VS, Andrews NR, Hicks CR, Peng H, Chiriva-Internati M, et al. Human papillomavirus DNA is present in a subset of unselected breast cancers. J Hum Virol. 2001;4(6):329-34. 
43. Li T, Lu ZM, Guo M, Wu QJ, Chen KN, Xing HP, et al. p53 codon 72 polymorphism (C/G) and the risk of human papillomavirus-associated carcinomas in China. Cancer. 2002;95(12):2571-6. doi:10.1002/cncr. 11008.

44. Damin AP, Karam R, Zettler CG, Caleffi M, Alexandre CO. Evidence for an association of human papillomavirus and breast carcinomas. Breast Cancer Res Treat. 2004;84(2):131-7. doi:10.1023/B:BREA.0000018411.89667.0d.

45. Bratthauer GL, Tavassoli FA, O'Leary TJ. Etiology of breast carcinoma: no apparent role for papillomavirus types 6/11/16/18. Pathol Res Pract. 1992; 188(3):384-6. doi:10.1016/50344-0338(11)81229-X.

46. Wrede D, Luqmani YA, Coombes RC, Vousden KH. Absence of HPV 16 and 18 DNA in breast cancer. Br J Cancer. 1992;65(6):891-4.

47. Lewensohn-Fuchs I, Berke Z, Wester D, Dalianis T, Elfgren K. Human papillomavirus (HPV) DNA is not detected in the peripheral blood cells of patients with cervical carcinoma. Genitourin Med. 1994;70(5):359-60

48. Gopalkrishna V, Singh UR, Sodhani P, Sharma JK, Hedau ST, Mandal AK, et al. Absence of human papillomavirus DNA in breast cancer as revealed by polymerase chain reaction. Breast Cancer Res Treat. 1996;39(2):197-202.

49. Dillner J, Arbyn M, Unger E, Dillner L. Monitoring of human papillomavirus vaccination. Clin Exp Immunol. 2011;163(1):17-25. doi:10.1111/j.1365-2249. 2010.04268.x.

50. Angulo M, Carvajal-Rodriguez A. Evidence of recombination within human alpha-papillomavirus. Virol J. 2007:4:33. doi:10.1186/1743-422X-4-33.

51. Anwar K, Inuzuka M, Shiraishi T, Nakakuki K. Detection of HPV DNA in neoplastic and non-neoplastic cervical specimens from Pakistan and Japan by non-isotopic in situ hybridization. Int J Cancer J Int Du Cancer. 1991; 47(5):675-80.

52. Kayani N, Sheikh A, Mithani C, Khurshid M. A View of HIV-1 Infection in Karachi. J Pakistan Med Assoc. 1994;44(1):8-11.

53. Shah SA, Khan OA, Kristensen S, Vermund SH. HIV-infected workers deported from the Gulf States: impact on southern Pakistan. Int J STD AIDS. 1999;10(12):812-4. doi:10.1258/0956462991913600.

54. Katoh K, Misawa K, Kuma K, Miyata T. MAFFT: a novel method for rapid multiple sequence alignment based on fast Fourier transform. Nucleic Acids Res. 2002:30(14):3059-66.

55. Sambrook J, Russel DW. Preparation of plasmid DNA by Alkaline Lysis with SDS: Minipreparation. In: Sambrook J, Russel DW, editors. Molecular cloning: a laboratory manual. 3rd ed. New York: Cold Spring Harbor; 2001. p. 1.32-1.4.

56. Kimura M. A simple method for estimating evolutionary rates of base substitutions through comparative studies of nucleotide sequence. J Mol Evol. 1980;16:111-20.

57. Tamura K, Peterson D, Peterson N, Stecher G, Nei M, Kumar S. MEGA5: molecular evolutionary genetics analysis using maximum likelihood, evolutionary distance and maximum parsimony methods. Mol Biol Evol. 2011;28(10):2731-9.

\section{Submit your next manuscript to BioMed Central and we will help you at every step:}

- We accept pre-submission inquiries

- Our selector tool helps you to find the most relevant journal

- We provide round the clock customer support

- Convenient online submission

- Thorough peer review

- Inclusion in PubMed and all major indexing services

- Maximum visibility for your research

Submit your manuscript at www.biomedcentral.com/submit
Biomed Central 